\title{
BMJ Open Postnatal depression and intimate partner violence: a nationwide clinic- based cross-sectional study in Malaysia
}

\author{
Noor Ani Ahmad, ${ }^{1}$ Umi Adzlin Silim, ${ }^{2}$ Azriman Rosman, ${ }^{3}$ Majdah Mohamed, ${ }^{3}$ \\ Ying Ying Chan, ${ }^{1}$ Noraida Mohd Kasim, ${ }^{1}$ Muslimah Yusof, ${ }^{1}$ \\ Mohamad Aznuddin Abd Razak, ${ }^{1}$ Maisarah Omar, ${ }^{1}$ Fazly Azry Abdul Aziz, ${ }^{1}$ \\ Rasidah Jamaluddin, ${ }^{1}$ Fatanah Ismail, ${ }^{3}$ Nurashikin Ibrahim, ${ }^{3}$ Tahir Aris ${ }^{1}$
}

To cite: Ahmad NA, Silim UA, Rosman $A$, et al. Postnatal depression and intimate partner violence: a nationwide clinic-based cross-sectional study in Malaysia. BMJ Open 2018;8:e020649. doi:10.1136/ bmjopen-2017-020649

- Prepublication history for this paper is available online. To view these files, please visit the journal online (http://dx.doi org/10.1136/bmjopen-2017020649).

Received 4 December 2017 Revised 25 March 2018 Accepted 13 April 2018

\section{Check for updates}

${ }^{1}$ Institute for Public Health, Ministry of Health Malaysia, Kuala Lumpur, Malaysia ${ }^{2}$ Hospital Kuala Lumpur, Ministry of Health Malaysia, Kuala Lumpur, Malaysia

${ }^{3}$ Public Health Department, Ministry of Health Malaysia, Kuala Lumpur, Malaysia

Correspondence to Dr Noor Ani Ahmad; drnoorani@moh.gov.my

\section{ABSTRACT}

Introduction An estimated 13\% of women in the postnatal period suffer from postnatal depression (PND) worldwide. In addition to underprivileged women, women who are exposed to violence are at higher risk of PND. This study aimed to investigate the relationship between intimate partner violence (IPV) and PND in Malaysia. Methods This survey was conducted as a nationwide cross-sectional study using a cluster sampling design. Probable PND was assessed using a selfadministered Edinburgh Postnatal Depression Scale (EPDS). Demographic profiles and IPV were assessed using a locally validated WHO Multicountry Study on Women's Health and Life Events Questionnaire that was administered in a face-to-face interview. An EPDS total score of 12 or more and/or a positive tendency to selfharm were used to define PND.

Results Out of 6669 women, 5727 respondents were successfully interviewed with a response rate of $85.9 \%$. The prevalence of probable PND was $4.4 \%(95 \% \mathrm{Cl} 2.9$ to 6.7). The overall prevalence of IPV was $4.9 \%(95 \% \mathrm{Cl} 3.8$ to 6.4$)$. Among the women in this group, $3.7 \%(95 \% \mathrm{Cl} 2.7$ to 5.0$), 2.6 \%$ (95\% Cl 1.9 to 3.5$)$ and $1.2 \%(95 \% \mathrm{Cl} 0.9$ to 1.7) experienced emotional, physical and sexual violence, respectively. Logistic regression analysis revealed that women who were exposed to IPV were at 2.3 times the risk for probable PND, with an adjusted $\mathrm{OR}(\mathrm{aOR})$ of 2.34 (95\% Cl 1.12 to 4.87). Other factors for PND were reported emotional violence (aOR 3.79, 95\% Cl 1.93 to 7.45 ), unplanned pregnancy (aOR $3.32,95 \% \mathrm{Cl} 2.35$ to 4.69 ), lack of family support during confinement (aOR 1.79, $95 \% \mathrm{Cl} 1.12$ to 2.87 ), partner's use of alcohol (aOR 1.59 , $95 \% \mathrm{Cl} 1.07$ to 2.35 ) or being from a household with a low income (aOR 2.99; 95\% Cl 1.63 to 5.49).

Conclusions Exposure to IPV was significantly associated with probable PND. Healthcare personnel should be trained to detect and manage both problems. An appropriate referral system and support should be made available.

\section{INTRODUCTION}

WHO estimates that $13 \%$ of women in the postpartum period experience mental disorders, with depression being particularly common. ${ }^{1}$ Depression has been observed to be higher

\section{Strengths and limitations of this study}

- A nationwide study using a cluster sampling design that allowed the findings of this study to be generalised to the overall Malaysian population as a majority of postnatal mothers seek care at government health facilities.

- Objective assessment of the potential causes of postnatal depression using a locally validated, self-administered Edinburgh Postnatal Depression Scale.

- Intimate partner violence was assessed using locally validated questionnaires.

- Postnatal depression was based on the screening tool and was not diagnostic.

in low-income and middle-income countries, ranging from $4.9 \%$ to $50.8 \%$ among mothers at 4-8 weeks post partum. ${ }^{2}$ According to self-reported questionnaires, the prevalence of depression among Asian women is $23.7 \%$, $16.5 \%$ and $17.4 \%$ at 6 weeks, 3 months and 6 months after childbirth, respectively. ${ }^{3}$ The prevalence in Malaysia varies based on the setting, with $20.7 \%$ in primary care settings ${ }^{4}$ and $31.7 \%$ in hospital settings. ${ }^{5}$

Postnatal depression (PND) generally occurs within 4-6weeks of childbirth and presents with symptoms such as an upset mood, anhedonia, forgetfulness, irritability, anxiety, sleep disturbances and poor functioning. ${ }^{6}$ Various factors were found to be associated with PND. A young maternal age; low socioeconomic status; partner's habits, such as alcoholism; lack of education; marital conflict; unsupportive partner and psychological factors, such as antenatal depression, stressful life events or intimate partner violence (IPV) are all associated with PND. ${ }^{2}{ }^{3}$ While depression at any time in a woman's life is devastating, depression during the perinatal, antenatal and postnatal 
periods is of special importance and is a public health concern due to its detrimental effects on women, families and their children. It can lead to serious complications, such as maternal suicide, child abuse and neglect and an increased risk of the child having emotional and behavioural problems later in life. ${ }^{7-10}$

IPV refers to any behaviour in an intimate relationship that causes physical, psychological or sexual harm to those in the relationship. Such behaviour includes acts of physical aggression, forced intercourse and other forms of sexual coercion and various controlling behaviours. ${ }^{11} \mathrm{IPV}$ is associated with fatal and non-fatal health effects, including homicide and suicide, as well as negative health behaviours during pregnancy, poor reproductive outcomes and adverse physical and mental consequences. ${ }^{12}$ IPV has been described as one of the most important predictors for depression in women. A review of studies exploring the determinants of PND in low-income and lower-middle-income countries reported an association between physical violence by intimate partners and PND. ${ }^{13}$ A household survey performed in Peninsular Malaysia revealed that $7.8 \%$ of women were emotionally abused, $5.0 \%$ were physically abused and $1.7 \%$ were sexually abused. ${ }^{14}$ However, this survey only targeted adult women and not women in the postpartum period.

There is an existing theoretical and conceptual framework that describes the hierarchical relationship between PND and its risk factors that is suitable for use in an epidemiological study. The framework divides determinants into three levels: proximal, intermediate and distal. ${ }^{15}$

Proximal determinants include violence and controlling behaviour from partners, and intermediate determinants encompass both partner and family factors, including the role of family support during confinement (figure 1). 'Confinement' is widely practised among Malaysian women after giving birth regardless of their socio-demographic and cultural differences. It is practised due to a belief that it is beneficial to women's well-being. ${ }^{16}$ During this period, family support in the form of accompaniment and caring for the mother is crucial. These behaviours may be the key protective element against PND rather than the ritual itself. ${ }^{1617}$

Although studies from several countries have shown a positive association between PND and IPV, currently no study has investigated the relationship between these factors in Malaysia. Thus, this study aimed to determine the magnitude of PND in Malaysia and its associated factors, with a particular focus on IPV. Although both conditions, PND and IPV, are pressing public health concerns worldwide, they are generally undetected by perinatal care services without proper screening programmes and interventions in place.

\section{METHODS \\ Study design}

This study was a nationwide clinic-based cross-sectional study. To ensure national representativeness, a cluster sampling design was used.

\section{Setting}

The study was conducted at the Maternal and Child Health Unit at government primary care clinics throughout Malaysia. Malaysia operates a dichotomous system with both public and private sectors. The Ministry of Health serves as the main provider of healthcare services. Health facilities are well distributed, with a mean distance of $8.4 \mathrm{~km} .{ }^{18}$ The majority $(98.2 \%)$ of women consulted 1 month after delivery with $>80 \%$ of the children received a primary vaccination at these government primary care clinics. ${ }^{19}$

\section{Participants}

Women who were at 6-16 weeks post partum and who registered at a government primary care clinic for postnatal care and/or child immunisation were eligible to be included in the sampling frame. Women who did not

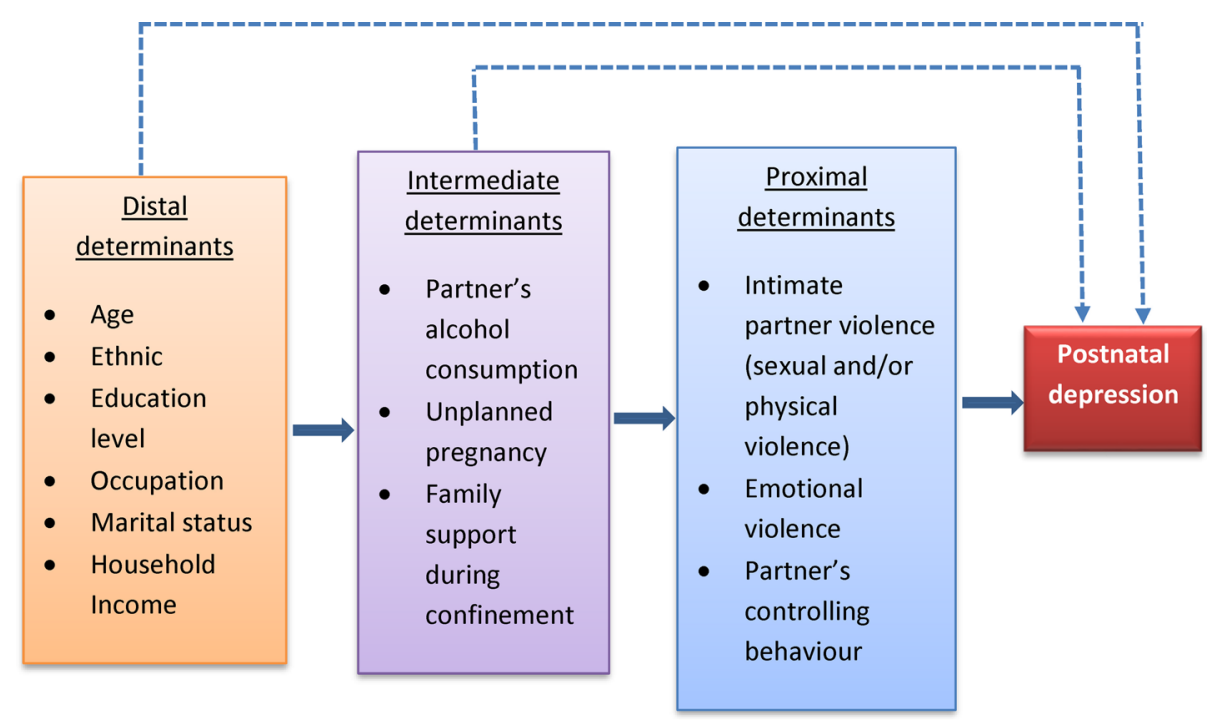

Figure 1 Conceptual framework illustrating the hierarchical model of risk factors for postnatal depression. 
register and/or were unable to communicate in either English or Bahasa Malaysia were not eligible.

\section{Recruitment strategies}

Sampling was performed by a resident statistician who was not directly involved in this study. Sampling was conducted using a two-stage random sampling design. The first stage used the sampling frame of all government primary care clinics in Malaysia. These clinics, considered to be clusters, were then randomly selected using the systematic probability proportionate to the size sampling technique. For the second stage, the sampling frame was formed from women between 6 and 16 weeks post partum who registered for a postnatal care and/or child immunisation at the randomly selected clinics and who were given consultation appointments between 1 June and 30 October 2016. The number of women selected from each state was then determined in proportion to the number of registered women. The clinic-based cards containing the women's profiles and the appointment dates were extracted and tagged to indicate eligible respondents.

The women were invited to join the study on the day of their appointment date. The women were given an Information Sheet and Consent Form by trained nurses at the registration counter. Those who consented to participate in the study were called into a private room within the clinic without their partners and were then given the self-administered Edinburgh Postnatal Depression Scale (EPDS) for assessment of PND. ${ }^{20}{ }^{21}$ On completion of the screening, the trained nurses conducted a face-toface interview in the same private room using the WHO Multicountry Study on Women's Health and Life Events Questionnaire. ${ }^{22}$ The questionnaire also included a few additional questions based on the variables in the conceptual framework. The added questions were tested for face validity before being used in this study.

Two nurses per selected clinic were given a 5-day training on interview techniques and were trained to handle PND and IPV, including the management and referral processes. The potential risk of interviewer bias was minimised by assessing interviewer skills during roleplay sessions and ad hoc supervision at the clinics by the research team members. The entire questionnaire, except the EPDS, was installed as web-based application into a mobile device with a built-in quality assessment feature and was administered as a computer-assisted personal interview. The responses from EPDS were manually entered into the application after the interview session ended. Data collection took place from 1 June through October 2016.

\section{Patient and public involvement}

Patients and public were not involved in either the development of the research question, study design or recruitment process. Patients who were detected as having probable PND or IPV were referred for appropriate management by the family physician at the respective clinics.

\section{Variables}

\section{Outcome variables}

The main outcome of this study, probable PND, was assessed using a self-administered locally validated EPDS. This scale is composed of 10 statements on common depressive symptoms that use Likert-type responses (0-3 scores) that reflect the severity of symptoms. Wan Mahmud et al found that, at a cut-off score of $11 / 12$, the sensitivity and specificity of the EPDS were $100 \%$ and $98.18 \%$, respectively. ${ }^{20}$ Another validation study recommended a cut-off score of 11.5 with a sensitivity of $72.7 \%$ and specificity of $92.6 \% .{ }^{21}$ In the first study, EPDS was tested against the International Statistical Classification of Diseases and Related Health Problems, 10th revision criteria, with assessment of its concurrent validity against the Malay version of the General Health Questionnaire and the Hamilton Depression Rating Scale (HDRS) score. ${ }^{20}$ The second study was tested and showed good correlations with both the Malay version of the Beck-Depression Inventory and HDRS. ${ }^{21}$ Based on these two studies and a consensus from the content expert, this study categorised women who had a total score of 12 or more and/or a positive response to question 10 on the risk of self-harm in the EPDS as having probable PND.

\section{Predictor variables}

IPV was defined as a single or repeated experience of physical and/or sexual violence. IPV was assessed based on the questionnaire used in the WHO Multicountry Study on Women's Health and Life Events. ${ }^{23}$ In this study, we used a locally validated questionnaire from Saddki $e t$ $a l$ that reported Cronbach's $\alpha$ values ranging from 0.767 to 0.858 across domains. ${ }^{22}$ Using this questionnaire, four types of violent behaviours were assessed: physical, sexual, emotional violence and controlling behaviour. Physical violence was defined as positive responses to a history of being slapped, pushed, beaten, kicked, choked or threatened with a weapon, and sexual violence was defined as a positive response for any history of sexual coercion, sex out of fear or forced to engage in a degrading sexual act. Emotional violence was defined as a positive response to ever having been insulted, publicly humiliated, intimidated or threatened or had a partner who threatened to hurt the respondent herself or someone she cared about. Controlling behaviour was defined as a positive response to ever having been kept away from friends and/or immediate family, partner insisting on knowing the participant's whereabouts at all times, treated indifferently, partner feeling angry if the participant spoke to another man, partner suspicious of the participant being unfaithful and/or expected permission to seek healthcare for herself by their former or present husbands/ partners. In this study, emotional violence and controlling behaviours were considered to be possible predictors for PND, and not part of IPV.

Other important predictors of PND are a lack of family support and unplanned pregnancy. Family support during confinement was defined as an answer 
of 'yes' to the questions "Did you observe a confinement period after your last child birth?" and "When you need help or have a problem, can you usually count on family members for support?" The response to the question "Was your last pregnancy planned or unplanned?" was used to categorise the pregnancy as planned or unplanned.

Possible confounding variables included age, ethnicity, marital status, education level, occupation and household income. Age was grouped into four categories: 18-24 years, 25-29 years, 30-34 years and 35 years and greater. Ethnicity was classified based on the major ethnic groups in Malaysia: Malay, Malaysian Chinese and Malaysian Indian and was followed by 'Other Bumiputera' and 'Other'. Other Bumiputera was composed of indigenous groups and local Sabahans and Sarawakians, and 'Other' was mostly composed of foreigners, immigrants, both legal and illegal, residing in Malaysia.

The education levels were categorised based on the Malaysian education system. Respondents were considered to have no formal education/primary education if they had not attended any formal schooling or had only completed up to 6 years of primary school. Those who had completed 11 years of formal schooling were defined as having completed secondary education while respondents with diplomas or higher qualifications were considered as having completed tertiary education. Household income was calculated based on the pooled income of family members and categorised into four groups.

\section{Sample size}

To the best of our knowledge, there is currently no information on the prevalence of IPV among women during the postnatal period in Malaysia. Thus, the sample size in this study was determined based on three available sources: a $20.7 \%$ prevalence of probable PND in Malaysia, ${ }^{4} 8.0 \%$ prevalence of IPV in Malaysia ${ }^{14}$ and $35.2 \%-38.9 \%$ prevalence of family violence among women with probable perinatal depression taken from a systematic review. ${ }^{24}$ To ensure an adequate sample size, the sample size was calculated based on the lowest prevalence $(8.0 \%)$ using a single proportion formula to estimate prevalence. Additionally, based on a design effect of 2 and an estimated non-response rate of $20 \%$, the required sample size was 6639 women.

\section{Data management and analysis}

Data from mobile devices were automatically uploaded into the server at the institute and converted into comma-separated values, CSV and Statistical Package of Social Sciences (SPSS) files. Only data with complete responses on the EPDS module were used for analysis. Data were analysed using the complex sample module in the IBM SPSS for Windows V.23.0 (IBM, Armonk, New York, USA) to account for the complexity of the sampling design. The final weights were calculated based on design weight and non-response weight, and a plan for analysis was created. Categorical variables were defined based on the variable operating definitions. Using the complex sample module, the overall prevalence of PND and estimated population affected by it were determined. Bivariate analysis was conducted to determine the factors associated with PND. Crude ORs were used to describe the strength of the associations between dependent and independent variables. A multivariable logistic regression model was fitted to determine the factors associated with PND. The primary predictor was IPV (physical and/or sexual violence). Other included independent variables were emotional violence, controlling behaviours, family support during confinement, unplanned pregnancy and partner's use of alcohol. Other possible confounders, such as ethnicity, respondent's age, marital status, education level, occupation and household income, were also included. We used a logistic regression model to produce a crude OR as a measure of the associations between PND and the independent variables. For the final model, a FORWARD LR variable selection method was used to identify significant variables. Only variables with $\mathrm{p}$ values $<0.25$ were included. The statistical significance of the individual regression coefficients was tested using the Wald $\mathrm{X}^{2}$ statistic. The adjusted OR (aOR), with the respective $95 \%$ CIs, was then calculated. A p value of $<0.05$ was considered significant. The model fit was tested using the Hosmer-Lemeshow statistic, which was non-significant $(\mathrm{p}>0.05)$.

\section{Ethics}

All participants gave their informed consent before participating. Identifiable data were not entered into the mobile device. Women who were found to be positive for EPDS and/or positive for any type of violence were referred to the Family Physician at the respective clinics for further management.

\section{RESULTS}

Out of 6639 randomly selected respondents, 5745 were successfully interviewed, but only 5727 completed the EPDS questions, resulting in a response rate of $85.9 \%$. A total of 442 respondents did not attend clinic appointments, were non-contactable, or moved out of the clinic's operation area during their eligibility period (6-16 weeks post partum). Another 452 respondents refused to participate, and 18 respondents had incomplete EPDS data (figure 2). No differences were found between the age, ethnicity or sex of respondents and non-respondents.

We used data from 5727 respondents in the analysis. The majority of respondents were between 25 and 35 years of age. The majority of respondents were married and had attained at least a secondary education level, and half of the respondents were working mothers (table 1).

\section{Prevalence of probable PND}

The prevalence of probable PND among women at 6-16 weeks post partum was $4.4 \%$ (95\% CI 2.9 to 6.7 ). There 


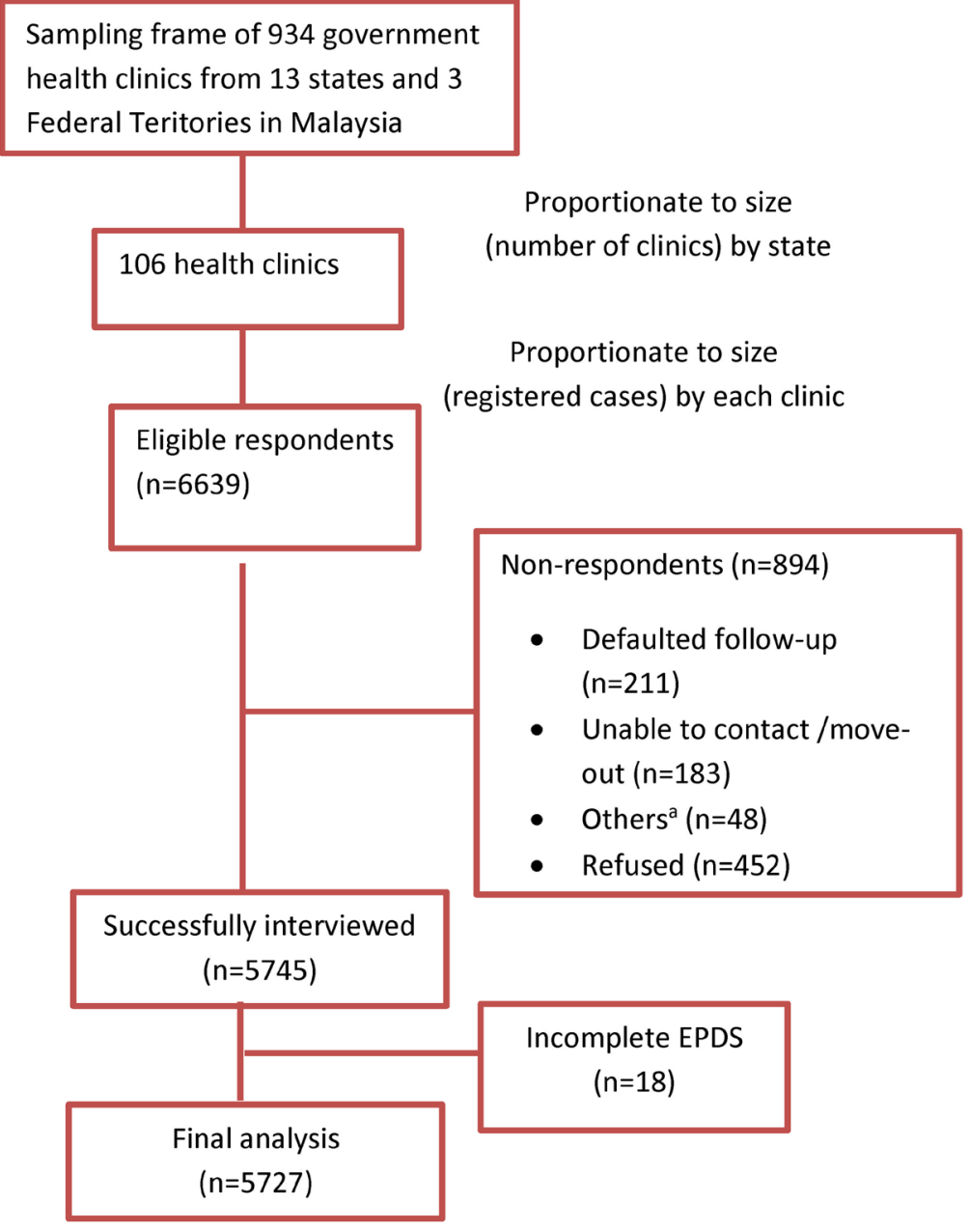

aOthers include communication/language barriers or duplicated name in the databaset

Figure 2 Flow diagram of respondent recruitment.

was no difference in prevalence in different age groups. The prevalence was higher among 'Other Bumiputeras' and 'Other' ethnicities compared with the Malays. Women who were unmarried, had a low education status, were not working and had low household incomes had a higher prevalence of probable PND. Women with partners who consumed alcohol, those with unplanned pregnancy and those without family support during confinement were also found to have a higher prevalence (table 2).

\section{Prevalence of IPV}

For partner violence, $3.7 \%$ (95\% CI 2.7 to 5.0 ), $2.6 \%$ (95\% CI 1.9 to 3.5 ) and $1.2 \%$ (95\% CI 0.9 to 1.7 ) of women had ever experienced emotional, physical or sexual violence, respectively. Controlling behaviour was experienced by 30.2\% (95\% CI 24.2 to 36.9) of women. Most of the violence occurred as combinations of emotional, sexual and physical violence. Analyses showed that $1.7 \%$, $0.7 \%$ and $0.5 \%$ reported experiencing only emotional violence, only physical violence and only sexual violence, respectively. Ever experiencing intimate partner sexual and/or physical violence was reported by $3.3 \%$ (95\% CI 2.5 to 4.3 ) of women.

\section{Factors associated with probable PND}

Multivariate analysis proved the relationship between IPV and probable PND. The odds of having probable PND doubled for women who had ever experienced IPV (aOR 2.34; $95 \%$ CI 1.12 to 4.87 ) after controlling for age, marital status, ethnicity, education level, occupation and partner's controlling behaviour. Probable PND was almost four times higher among women who had ever experienced emotional violence (aOR 3.79; 95\% CI 1.93 to 7.45 ) after controlling for other variables. Additionally, probable PND was three times higher in women with unplanned pregnancies (aOR 3.32; 95\% CI 2.35 to 4.69 ), $79 \%$ higher among those who lacked family support during confinement (aOR 1.79; 95\% CI 1.12 to 2.87), 59\% higher among those who reported partner alcohol consumption (aOR $1.59,95 \%$ CI 1.07 to 2.35 ) and was three times higher in women with household incomes of $<$ RM1500 (aOR 2.99; $95 \%$ CI 1.63 to 5.49 ) compared with those who earned $>$ RM5000 (table 3). 


\begin{tabular}{|c|c|c|}
\hline & $\begin{array}{l}\text { Unweighted } \\
\text { count }\end{array}$ & $\begin{array}{l}\text { Percentage } \\
\text { (\%) }\end{array}$ \\
\hline \multicolumn{3}{|l|}{ Age (years) } \\
\hline $18-24$ & 1043 & 18.2 \\
\hline $25-29$ & 1842 & 32.2 \\
\hline $30-34$ & 1749 & 30.5 \\
\hline 35 and above & 1093 & 19.1 \\
\hline \multicolumn{3}{|l|}{ Ethnicity } \\
\hline Malay & 3889 & 67.9 \\
\hline Malaysian Chinese & 549 & 9.6 \\
\hline Malaysian Indians & 262 & 4.6 \\
\hline Other Bumiputeras & 753 & 13.1 \\
\hline Others & 274 & 4.8 \\
\hline \multicolumn{3}{|l|}{ Marital status } \\
\hline Married/has partner & 5654 & 98.7 \\
\hline $\begin{array}{l}\text { Not married/no current } \\
\text { partner }\end{array}$ & 73 & 1.3 \\
\hline \multicolumn{3}{|l|}{ Education level } \\
\hline No formal/primary & 382 & 7.2 \\
\hline Secondary & 3300 & 60.0 \\
\hline Tertiary & 2045 & 32.8 \\
\hline \multicolumn{3}{|l|}{ Occupation } \\
\hline Working & 2807 & 49.0 \\
\hline Not working/housewife & 2920 & 51.0 \\
\hline \multicolumn{3}{|c|}{ Household income ${ }^{*}$} \\
\hline$<\mathrm{RM} 1500$ & 1575 & 27.5 \\
\hline RM1501-RM3000 & 1879 & 32.8 \\
\hline RM3001-RM5000 & 1308 & 22.9 \\
\hline RM5001 and more & 958 & 16.7 \\
\hline
\end{tabular}

*Missing data=7; 1US\$=RM3.89 (currency exchange on 3 February 2018).

\section{DISCUSSION}

To our knowledge, this is the first study to investigate the relationship between probable PND and IPV using a large number of respondents in Malaysia. This study examined the factors associated with probable PND, with IPV being the main predictor. An earlier population-based study observed that IPV was a significant public health concern in Malaysia, ${ }^{14}$ and studies on PND have also demonstrated its importance. ${ }^{45}$ Our study clearly demonstrated the relationship between these two problems, which has implications for planning future services and intervention strategies.

\section{Prevalence of probable PND}

The prevalence of probable PND (4.4\%) in our study was lower than that reported in an earlier study conducted in Kelantan, one of the states in Malaysia (20.3\%). ${ }^{4}$ Both studies were conducted at primary care clinics and used
Table 2 Factors associated with probable postnatal depression $(n=5727)$

\begin{tabular}{|c|c|c|}
\hline Variables & $\begin{array}{l}\text { Prevalence } \\
(95 \% \mathrm{Cl})\end{array}$ & $\begin{array}{l}\text { Crude OR } \\
(95 \% \mathrm{Cl})\end{array}$ \\
\hline \multicolumn{3}{|l|}{ Respondent's age (years) } \\
\hline $18-24$ & 6.9 (3.8 to 12.4$)$ & 1.49 (0.96 to 2.13$)$ \\
\hline $25-29$ & 4.6 (3.0 to 7.2$)$ & 0.93 (0.63 to 1.37 ) \\
\hline $30-34$ & 3.1 (1.9 to 4.8$)$ & $0.69(0.45$ to 1.04$)$ \\
\hline 35 and above & $4.0(2.2$ to 7.1$)$ & $\mathrm{R}$ \\
\hline \multicolumn{3}{|l|}{ Ethnicity } \\
\hline Malay & 3.7 (2.5 to 5.5$)$ & $\mathrm{R}$ \\
\hline Malaysian Chinese & 1.7 (0.8 to 3.7$)$ & 0.69 (0.38 to 1.26$)$ \\
\hline Malaysian Indian & 4.5 (2.0 to 9.7$)$ & $1.48(0.81$ to 2.72$)$ \\
\hline Other Bumiputeras & 9.1 (3.6 to 20.9 ) & 2.63 (1.90 to 3.62$)$ \\
\hline Others & 5.1 (2.3 to 10.5$)$ & $1.92(1.12$ to 3.27$)$ \\
\hline \multicolumn{3}{|l|}{ Marital status (current) } \\
\hline Married/has partner & 4.2 (2.7 to 6.5$)$ & $\mathrm{R}$ \\
\hline $\begin{array}{l}\text { Unmarried/no current } \\
\text { partner }\end{array}$ & 17.6 (7.1 to 37.5$)$ & 3.14 (1.49 to 6.64$)$ \\
\hline \multicolumn{3}{|l|}{ Education level } \\
\hline $\begin{array}{l}\text { No formal/primary } \\
\text { education }\end{array}$ & $8.9(3.5$ to 20.9$)$ & 2.46 (1.53 to 3.95$)$ \\
\hline Secondary education & 4.7 (3.1 to 6.9$)$ & 1.45 (1.06 to 1.97$)$ \\
\hline Tertiary education & 2.9 (1.8 to 4.6$)$ & $\mathrm{R}$ \\
\hline \multicolumn{3}{|l|}{ Occupation } \\
\hline Working & 2.5 (1.5 to 4.1$)$ & $\mathrm{R}$ \\
\hline $\begin{array}{l}\text { Not working/ } \\
\text { housewife }\end{array}$ & 6.1 (3.9 to 9.5$)$ & 1.88 (1.42 to 2.49$)$ \\
\hline \multicolumn{3}{|l|}{ Household income } \\
\hline$<\mathrm{RM} 1500$ & 8.5 (5.0 to 13.9$)$ & 3.75 (2.29 to 6.14$)$ \\
\hline RM1500-RM3000 & 3.4 (2.3 to 5.0$)$ & 1.74 (1.04 to 2.93$)$ \\
\hline RM3001-RM5000 & $2.2(1.2$ to 3.9$)$ & 1.00 (0.55 to 1.82$)$ \\
\hline RM5001 and more & & $\mathrm{R}$ \\
\hline \multicolumn{3}{|l|}{ Unplanned pregnancy } \\
\hline Yes & 11.5 (5.6 to 22.2) & 4.19 (3.10 to 5.67$)$ \\
\hline No & 2.7 (1.7 to 4.1$)$ & $\mathrm{R}$ \\
\hline \multicolumn{3}{|c|}{ Partner's consumed alcohol } \\
\hline Yes & $5.6(3.3$ to 9.4$)$ & 1.71 (1.20 to 2.42$)$ \\
\hline No & $3.5(2.2$ to 5.5$)$ & $\mathrm{R}$ \\
\hline \multicolumn{3}{|c|}{ Lack of family support during confinement } \\
\hline Yes & $10.8(6.2$ to 18.1$)$ & 2.80 (1.96 to 3.99$)$ \\
\hline No & $3.8(2.5$ to 5.7$)$ & $\mathrm{R}$ \\
\hline \multicolumn{3}{|l|}{ Emotional violence } \\
\hline Yes & $27.1(18.1$ to 38.4$)$ & $8.94(6.21$ to 12.87$)$ \\
\hline No & 3.5 (2.2 to 5.8$)$ & $\mathrm{R}$ \\
\hline \multicolumn{3}{|l|}{ Physical violence } \\
\hline Yes & 29.7 (19.4 to 42.6$)$ & 7.50 (4.75 to 11.83$)$ \\
\hline No & 3.7 (2.3 to 6.0$)$ & $\mathrm{R}$ \\
\hline \multicolumn{3}{|l|}{ Sexual violence } \\
\hline Yes & 43.8 (27.9 to 61.1$)$ & 15.10 (8.91 to 25.60$)$ \\
\hline No & 3.9 (2.4 to 6.2$)$ & $\mathrm{R}$ \\
\hline
\end{tabular}

Continued 


\begin{tabular}{|c|c|c|}
\hline Variables & $\begin{array}{l}\text { Prevalence } \\
(95 \% \mathrm{Cl})\end{array}$ & $\begin{array}{l}\text { Crude OR } \\
(95 \% \mathrm{Cl})\end{array}$ \\
\hline \multicolumn{3}{|c|}{ Partner's controlling behaviour } \\
\hline Yes & $7.2(5.0$ to 10.1$)$ & 2.31 (1.76 to 3.03 ) \\
\hline No & $3.2(1.7$ to 6.1$)$ & $\mathrm{R}$ \\
\hline \multicolumn{3}{|c|}{ Intimate partner violence ${ }^{*}$} \\
\hline Yes & 32.6 (22.8 to 44.1$)$ & 9.32 (6.29 to 13.82$)$ \\
\hline No & 3.5 (2.1 to 5.7$)$ & $\mathrm{R}$ \\
\hline
\end{tabular}

*1US \$=RM3.89 (currency exchange on 3 February 2018); R=reference

similar screening tools with similar cut-off scores, but targeted women at different times during the postpartum period. Our nationwide study targeted women at 6-16 weeks post partum, while the Kelantan study targeted women at 4-6 weeks post partum. The difference in the prevalence might be due to the different screening timings. Longitudinal studies have reported that incidence rates decrease over the postpartum period. ${ }^{25} 26$

Table 3 Multivariate analysis of the factors associated with probable postnatal depression $(n=5727)$

\begin{tabular}{|c|c|c|c|}
\hline Variables & $\begin{array}{l}\text { Wald X }{ }^{2} \\
\text { statistic }\end{array}$ & $\begin{array}{l}\text { Adjusted OR } \\
(95 \% \mathrm{Cl})\end{array}$ & $P$ values \\
\hline \multicolumn{4}{|c|}{ Intimate partner violence } \\
\hline Yes & 5.141 & $2.34(1.12$ to 4.87$)$ & 0.023 \\
\hline No & & $\mathrm{R}$ & \\
\hline \multicolumn{4}{|c|}{ Emotional violence } \\
\hline Yes & 14.935 & $3.79(1.93$ to 7.45$)$ & $<0.001$ \\
\hline No & & $\mathrm{R}$ & \\
\hline \multicolumn{4}{|c|}{ Unplanned pregnancy } \\
\hline Yes & 46.591 & 3.32 (2.35 to 4.69$)$ & $<0.001$ \\
\hline No & & $\mathrm{R}$ & \\
\hline \multicolumn{4}{|c|}{ Lack of family support during confinement } \\
\hline Yes & 5.999 & 1.79 (1.12 to 2.87$)$ & 0.014 \\
\hline No & & $\mathrm{R}$ & \\
\hline \multicolumn{4}{|c|}{ Partner consumed alcohol } \\
\hline Yes & 5.351 & 1.59 (1.07 to 2.35$)$ & 0.021 \\
\hline No & & $\mathrm{R}$ & \\
\hline \multicolumn{4}{|c|}{ Household income } \\
\hline$<$ RM1500 & 12.438 & 2.99 (1.63 to 5.49$)$ & $<0.001$ \\
\hline $\begin{array}{l}\text { RM1500- } \\
\text { RM3000 }\end{array}$ & 3.459 & $1.82(0.97$ to 3.41$)$ & 0.063 \\
\hline $\begin{array}{l}\text { RM3001- } \\
\text { RM5000 }\end{array}$ & 0.054 & 1.09 (0.53 to 2.23$)$ & 0.816 \\
\hline $\begin{array}{l}\text { RM5001 } \\
\text { and more }\end{array}$ & & $\mathrm{R}$ & \\
\hline
\end{tabular}

Controlled for age, marital status, education level, occupation, ethnicity and partner's controlling behaviour.

$\mathrm{R}=$ reference
Accordingly, the prevalence in this study was also lower than that reported by an earlier nationwide household survey conducted in Malaysia using a similar screening tool and target population. This earlier survey reported a prevalence of probable PND of $12.7 \% .{ }^{27}$ Another possible reason for the lower prevalence in this study was the reluctance of women to disclose their problem, possibly due to a fear of being stigmatised. The clinic environment may not have been conducive for conducting a study examining sensitive issues. PND and IPV are relatively hidden in our community, and it is possible that we would have observed a higher prevalence if we had been able to create awareness and desensitise the issues before beginning this study. However, the prevalence found by this study is comparable to that reported by a study in Indonesia $(6.6 \%)$ among women at 6 weeks post partum that used a similar cut-off score as well as a study conducted in Singapore $(6.8 \%)$ among a similar target group but that used a lower cut-off score. ${ }^{2}$

\section{Association between IPV and probable PND}

Our study demonstrated a significant association between probable PND and IPV (defined as a single occurrence of/ repeated physical and/or sexual violence). This finding concurs with previous studies that recorded the independent effect of IPV with PND. ${ }^{24}$ 28-32 The effect of IPV on women's mental health was not related to the time of occurrence. Khalifa et al described a history of violence as the strongest determinant of PND, ${ }^{28}$ while studies in France and Bangladesh have supported an association between PND and experiencing IPV before or during pregnancy. ${ }^{31}{ }^{32}$ A prospective study among Norwegian mothers also showed higher risks of PND among women with a history of exposure to adult abuse, including sexual abuse. ${ }^{33}$ We also recorded a strong association between emotional violence and the occurrence of probable PND, even after adjusting for partner's controlling behaviour and other confounding variables. The psychological effects of emotional violence on PND was more prominent than those of IPV, which has also been seen in other studies. ${ }^{34-37}$ Emotional violence has a negative impact on the emotional and mental health of women in the postpartum period and often contributes to physical or sexual violence. ${ }^{38}$

\section{Other factors associated with probable PND}

Other than IPV, we also noted an increased likelihood of probable PND among mothers from low-income families, those with partners who consumed alcohol and those who experienced a lack of support during confinement. Financial difficulties have been identified as a risk factor for PND, independent of IPV. ${ }^{13} 3039$ The association of PND with partner substance use was also observed in a Canadian study. ${ }^{39}$ Substance use by husbands/partners is often associated with IPV, which may contribute to the PND problem in women. ${ }^{28}$ Family support during confinement is very important in Asian communities. Our study demonstrated that a lack of family support during confinement is independently associated with an increased likelihood 
of PND. Our findings concur with other studies that have demonstrated similar associations. ${ }^{13} 4041$ A study from China concluded that a lack of postnatal family support, particularly support from the husband, is an important risk factor for PND. ${ }^{42}$ We observed that marital status, the education level and occupation do not contribute directly to PND. As in many Asian countries, women in Malaysia are primarily expected to care for children and manage household chores, as prescribed by traditional gender roles, regardless of whether they are working. ${ }^{43}$ These cultural norms may assign an inferior status to women and lead to misconceptions that may cause women to blame themselves, minimise abuse and prevent them from seeking help when abuse occurs. Perpetrators may manipulate cultural practices or religious teachings to make it seems as if it supports IPV. Many women struggle because they believe that their husbands have the right to beat them, a belief originating from misinterpreted religious teachings. ${ }^{44}$ By contrast, women in Malaysia are more empowered, as evidenced by the increasing number of educated women and women in the workforce, and this may challenge the traditional view of gender roles. ${ }^{43}$ The stronger affiliation to religion and its true teaching among Asians can have a protective effect against IPV, as religion promotes general commitment to family life, regards the institution of marriage highly and provides an understanding of women's rights. ${ }^{44}$ Interestingly, a large prevalence study on IPV in Malaysia found that $83 \%$ of women who experienced IPV were assertive in seeking help for their survival in abusive relationships rather than continuing to suffer in silence. ${ }^{45}$

\section{Strengths and limitations}

The main strength of our study is its use of large nationally representative data with robust methods. Moreover, the response rate was relatively high $(85.9 \%)$ despite the sensitive nature of the issue. We also examined various sociodemographic and sociocultural factors. Most importantly, this study used an internationally recognised tool that was locally validated and data collectors received a standardised training. Nevertheless, our findings have several limitations. One of the limitation of this study was the cross-sectional nature of the study, which prevents the determination of temporal relationships between exposure to IPV and probable PND. Although this study adjusted for a substantial number of possible confounders, some important variables were not studied, such as birth complications, child morbidity and breast feeding. Additionally, we were only able to identify probable PND using a screening tool without further diagnostic confirmation process. It is also acknowledged that 'PND' is an umbrella term rather than a distinct psychological state. The term 'postpartum depression' encompasses several mood disorders that follow childbirth, including anxiety disorders, trauma and adjustment reactions. ${ }^{46}$ This broad spectrum of perinatal mental health may be associated with different sets of risk factors that may or may not overlap with each other, thus confounding the outcome of this study. Furthermore, the WHO tool used to identify IPV, while used widely, may not be exhaustive in terms of types of violence it identifies, which may have underestimated the prevalence of IPV in this study. However, despite these limitations, this study was able to provide a baseline and offers insight into the association between IPV and probable PND in Malaysia.

\section{CONCLUSION AND POLICY IMPLICATIONS}

Higher odds of probable PND were observed among women with a history of IPV. Women who were exposed to emotional violence, those with husbands who consumed alcohol, those with a lack of family support during confinement and those from low-income families were also at risk of PND. Pregnancy care and postnatal programmes must address issues related to PND and IPV as there is overwhelming evidence of adverse health effects for both the mother and child. Healthcare personnel must be professionally trained to detect and confidently communicate these issues. There must be a proper setting as well as trained personnel to provide help and proper counselling or referrals for these women. Issues pertaining to sexual and reproductive health, women's rights and violence should be incorporated into the well-established premarital course ${ }^{47}$ Courses on family values and parenting skills for young couples and parents could be another platform.

Acknowledgements The authors would like to thank the Director General of Health Malaysia for his permission to publish this article. The authors would also like to thank the Asia Pacific International Research and Education (ASPIRE) Network, for their contribution to the concept of this study.

Contributors NAA, UAS and TA were responsible for the study design and concept. NAA was responsible for the study conduct, respondent selection, study implementation, data analysis, data interpretation, drafting, critical revision and final approval of the manuscript. UAS, AR, MM and YYC were responsible for drafting, critical revision and final approval of the manuscript. NMK, MY, AAR, MO, FAAA and RJ were responsible for respondent recruitment, data collection, data entry, critical revision and final approval of the manuscript. Fl and NI were responsible for data interpretation, critical revision and final approval of the manuscript.

Funding This study was supported by the Ministry of Health Research Grant (NMRR-15-2404-26677).

Competing interests None declared.

Patient consent Obtained.

Ethics approval Approval from the Medical Research and Committee, Ministry of Health Malaysia was obtained prior to the implementation of this study (NMRR-15-2404-26677).

Provenance and peer review Not commissioned; externally peer reviewed.

Data sharing statement The data used for this study are not publicly available. However, the data are available from the corresponding author on reasonable request and with permission of the Director General of Health Malaysia.

Open Access This is an Open Access article distributed in accordance with the Creative Commons Attribution Non Commercial (CC BY-NC 4.0) license, which permits others to distribute, remix, adapt, build upon this work non-commercially, and license their derivative works on different terms, provided the original work is properly cited and the use is non-commercial. See: http://creativecommons.org/ licenses/by-nc/4.0/

(C) Article author(s) (or their employer(s) unless otherwise stated in the text of the article) 2018. All rights reserved. No commercial use is permitted unless otherwise expressly granted. 


\section{REFERENCES}

1. World Health Organization. Mental Health: Maternal mental health. http://www.who.int/mental_health/maternal-child/maternal_mental_ health/en/ (accessed 15 May 2017).

2. Norhayati MN, Hazlina NH, Asrenee AR, et al. Magnitude and risk factors for postpartum symptoms: a literature review. J Affect Disord 2015;175:34-52

3. Roomruangwong C. Perinatal depression in Asian women: prevalence, associated factors, and cultural aspects. Asian Biomedicine 2011;5:179-93.

4. Kadir AA, Nordin R, Ismail SB, et al. Postnatal depression in mothers attending primary care clinics in Kelantan, Malaysia. International Medical Journal 2005;12:105-9.

5. Ariffin Siti RM, Ahmad A, Rahman RA, et al. Postpartum depression in Malaysian women: the association with the timing of pregnancy and sense of personal control during childbirth. Int.J. Acad.Res 2014;6:143-9.

6. American Psychiatric Association. Diagnostic and statistical manual of mental disorders. 5th edn. Washington: DC, 2000

7. Paris R, Bolton RE, Weinberg MK, et al. suicidality, and mother-infant interactions. Arch Womens Ment Health 2009;12:309-21.

8. American Academy of Pediatrics. Clinical report - incorporating recognition and management of perintal and postpartum depression into Pediatric practice. www.pediatrics.org/cgi/doi/10.1542/peds. 2010-2348

9. Pearson RM, Evans J, Kounali D, et al. Maternal depression during pregnancy and the postnatal period: risks and possible mechanisms for offspring depression at age 18 years. JAMA Psychiatry 2013;70:1312-9.

10. Murray L, Arteche A, Fearon P, et al. Maternal postnatal depression and the development of depression in offspring up to 16 years of age. J Am Acad Child Adolesc Psychiatry 2011;50:460-70.

11. Krug EG, Mercy JA, Dahlberg LL, et al. The world report on violence and health. Lancet 2002;360:1083-8.

12. Department of Reproductive Health and Reserach. Global and regional estimates of violence against women: prevalence and health effects of intimate partner violence and non-partner sexual violence: World Health Organization, 2013.

13. Fisher J, Cabral de Mello M, Patel V, et al. Prevalence and determinants of common perinatal mental disorders in women in low- and lower-middle-income countries: a systematic review. Bull World Health Organ 2012;90:139-49.

14. Shuib R, Endut N, Ali SH, et al. Domestic Violence and Women's Well-being in Malaysia: Issues and Challenges Conducting a National Study Using the WHO Multi-country Questionnaire on Women's Health and Domestic Violence Against Women. Procedia Soc Behav Sci 2013;91:475-88.

15. Victora CG, Huttly SR, Fuchs SC, et al. The role of conceptual frameworks in epidemiological analysis: a hierarchical approach. Int $J$ Epidemiol 1997;26:224-7.

16. Hishamshah M, Ramzan M, Rashid A, et al. Belief and practices of traditional postpartum care among a rural community in Penang Malaysia. The Internet Journal of Third World Medicine 2010;9:1-9.

17. Klainin P, Arthur DG. Postpartum depression in Asian cultures: a literature review. Int J Nurs Stud 2009;46:1355-73.

18. Institute for Public Health and Institute for Health Systems Research. National Health and Morbidity Survey (NHMS) 2011: Healthcare Demands and Out-of-Pocket Health Expenditure. Volume III. ISBN 978-983-3887-77-4.

19. Institute for Public Health (IPH), Ministry of Health Malaysia. National Health and Morbidity Survey (NHMS) 2016: Maternal and Child Health. 2016:Vol II: Findings. 272. ISBN:978-983-2387-28-2. http:// www.iku.gov.my

20. Mahmud WM, Awang A, Mohamed MN. Revalidation of the Malay Version of the Edinburgh Postnatal Depression Scale (EPDS) Among Malay Postpartum Women Attending the Bakar Bata Health Center in Alor Setar, Kedah, North West Of Peninsular Malaysia. Malays J Med Sci 2003;10:71-5.

21. Abdul Kadir A, Nordin R, Ismail SB, et al. Validation of the Malay version of Edinburgh Postnatal Depression Scale for Postnatal women in Kelantan, Malaysia. Asia Pac Fam Med 2004;3:9-18.

22. Saddki N, Sulaiman Z, Ali SH, et al. Validity and reliability of the Malay version of WHO Women's Health and Life Experiences Questionnaire. J Interpers Violence 2013;28:2557-80.

23. World Health Organization. WHO Multi-country Study on Women's Health and Life Events Questionnaire (version 9.9). WHO multicountry study on women's health and domestic violence against women: initial results on prevalence, health outcomes and women's responses. Geneva: Switzerland, 2005.

24. Howard LM, Oram S, Galley H, et al. Domestic violence and perinatal mental disorders: a systematic review and meta-analysis. PLoS Med 2013;10:e1001452.

25. Abdollahi F, Zarghami M, Azhar MZ, et al. Predictors and incidence of post-partum depression: a longitudinal cohort study. J Obstet Gynaecol Res 2014;40:2191-200.

26. Escribà-Agüir V, Artazcoz L. Gender differences in postpartum depression: a longitudinal cohort study. J Epidemiol Community Health 2011;65:320-6.

27. Institute for Public Health (IPH), National Institutes of Health, Ministry of Health Malaysia. National Health and Morbidity Survey (NHMS) 2016: Maternal and Child Health. Vol. II: Findings. 2016. http://www. iku.gov.my

28. Khalifa DS, Glavin K, Bjertness E, et al. Determinants of postnatal depression in Sudanese women at 3 months postpartum: a crosssectional study. BMJ Open 2016;6:e009443.

29. Nongrum R, Thomas E, Lionel J, et al. Domestic violence as a risk factor for maternal depression and neonatal outcomes: a hospitalbased cohort study. Indian J Psychol Med 2014;36:179-81.

30. Nasreen HE, Edhborg M, Petzold M, et al. Incidence and risk factors of postpartum depressive symptoms in women: a population-based prospective cohort study in a rural district in Bangladesh. J Depress Anxiety 2015;4:2.

31. Gaillard A, Le Strat Y, Mandelbrot L, et al. Predictors of postpartum depression: prospective study of 264 women followed during pregnancy and postpartum. Psychiatry Res 2014;215:341-6.

32. Islam MJ, Broidy L, Baird K, et al. Intimate partner violence around the time of pregnancy and postpartum depression: The experience of women of Bangladesh. PLoS One 2017;12:e0176211.

33. Sørbø MF, Grimstad H, Bjørngaard JH, et al. Adult physical, sexual, and emotional abuse and postpartum depression, a population based, prospective study of 53,065 women in the Norwegian Mother and Child Cohort Study. BMC Pregnancy Childbirth 2014;14:316.

34. Shamu S, Zarowsky C, Roelens K, et al. High-frequency intimate partner violence during pregnancy, postnatal depression and suicidal tendencies in Harare, Zimbabwe. Gen Hosp Psychiatry 2016;38:109-14.

35. Ludermir AB, Lewis G, Valongueiro SA, et al. Violence against women by their intimate partner during pregnancy and postnatal depression: a prospective cohort study. Lancet 2010;376:903-10.

36. Zhang Y, Zou S, Cao Y, et al. Relationship between domestic violence and postnatal depression among pregnant Chinese women. Int J Gynaecol Obstet 2012;116:26-30.

37. Desmarais SL, Pritchard A, Lowder EM, et al. Intimate partner abuse before and during pregnancy as risk factors for postpartum mental health problems. BMC Pregnancy Childbirth 2014;14:132.

38. Miura A, Fujiwara T. Intimate Partner Violence during Pregnancy and Postpartum Depression in Japan: A Cross-sectional Study. Front Public Health 2017;5:81.

39. Dennis CL, Vigod S. The relationship between postpartum depression, domestic violence, childhood violence, and substance use: epidemiologic study of a large community sample. Violence Against Women 2013;19:503-17.

40. de Castro F, Place JMS, Billings DL, et al. Risk profiles associated with postnatal depressive symptoms among women in a public sector hospital in Mexico: the role of sociodemographic and psychosocial factors. Arch Womens Ment Health 2015;18:463-71.

41. Jones E, Coast E. Social relationships and postpartum depression in South Asia: a systematic review. Int J Soc Psychiatry 2013;59:690-700.

42. Xie RH, Yang J, Liao S, et al. Prenatal family support, postnatal family support and postpartum depression. Aust N Z J Obstet Gynaecol 2010;50:340-5.

43. Abdullah K, Noor NM, Wok S. The Perceptions of Women's Roles and Progress: A Study of Malay Women. Soc Indic Res 2008;89:439-55.

44. Ibrahim N, Abdalla M. A Critical Examination of Qur'an 4:34 and Its Relevance to Intimate Partner Violence in Muslim Families. J Muslim Ment Health 2010;5:327-49.

45. Oon SW, Shuib R, Ali SH, et al. Exploring the coping mechanism of women experiencing Intimate Partner Violence in Malaysia. IJASOS 2016;11:820-5.

46. Thurgood S, Avery D, Williamson L. Postpartum Depression (PPD) American Journal of Clinical Medicine 2009;6:17-22.

47. Senediak C. The Value of Premarital Education. Australian and New Zealand Journal of Family Therapy 1990;11:26-31. 